\title{
IMPACT OF SEGMENTATION PARAMETERS ON THE CLASSIFICATION OF VHR IMAGES ACQUIRED BY RPAS
}

\author{
M. G. Lacerda ${ }^{1,2,{ }^{*}}$, E. H. Shiguemori ${ }^{1,3}$, A. J. Damião ${ }^{1,2}$, C. S. Anjos ${ }^{4, * *}$, M. Habermann ${ }^{1}$ \\ ${ }^{1}$ Institute for Advanced Studies - IEAv, São José dos Campos-SP, Brazil - (marielcio,elcio,damiao, habermann)@ieav.cta.br \\ ${ }^{2}$ Aeronautics Institute of Technology - ITA, São José dos Campos-SP, Brazil \\ ${ }^{3}$ National Institute for Space Research - INPE, São José dos Campos-SP, Brazil \\ ${ }^{4}$ Federal Institute of Education, Science and Technology of South of Minas Gerais - IFSULDEMINAS, Inconfidentes-MG, Brazil \\ - (camila.lacerda@ifsuldeminas.edu.br) \\ * IEEE Student Member ${ }^{* *}$ IEEE Member
}

ICWG

KEY WORDS: Image Classification, Segmentation Parameters, RPA, Very High Resolution Images

\begin{abstract}
:
RPAs (Remotely Piloted Aircrafts) have been used in many Remote Sensing applications, featuring high-quality imaging sensors. In some situations, the images are interpreted in an automated fashion using object-oriented classification. In this case, the first step is segmentation. However, the setting of segmentation parameters such as scale, shape, and compactness may yield too many different segmentations, thus it is necessary to understand the influence of those parameters on the final output. This paper compares 24 segmentation parameter sets by taking into account classification scores. The results indicate that the segmentation parameters exert influence on both classification accuracy and processing time.
\end{abstract}

\section{INTRODUCTION}

Small RPAs, also known as drones, are increasingly present on both military and civilian activities, due to their low cost and small size (Granemann, 2018).

Such aircrafts, in general, are equipped with imaging sensors capable of generating VHR (Very High Resolution) images, with GSD (Ground Sample Distance) of few centimeters. Moreover, they can carry sensors that work on different regions of the electromagnetic spectrum, ranging from visible light to infrared.

However, there is no point in having a drone with such a capacity if we cannot turn those data into useful information at the right time. Sometimes, it is imperative to have the information about a given region in a quick and precise manner, to support the decision-maker during sensitive missions (Lacerda et al., 2017).

Thus, image interpretation is an essential tool, because it transforms image data into useful information, with high accuracy and a few time. The precise classification of the image is important to provide confidence on image interpretation (Lacerda et al., 2019) and (Geotecnologias, 2010).

When it comes to high spatial resolution image classification, the best results are those that consider an object-oriented approach. In this case, the pixels belonging to a given pixel bear similar spectral signature, and this pixel set is considered a segment (Geotecnologias, 2010). A good image segmentation can separate the objects in a scene, and it depends on the correct choice of segmentation parameters set (Gonzalez, Woods, 2010).

In this context, this work aims at evaluating the relationship between classification accuracy and image segmentation with different parameter sets. The resulting classification accuracies are compared in a confusion matrix, from where Overall Accuracy and Kappa Index are calculated (Foody, 2002).

\section{IMAGE ACQUISITION AND PROCESSING}

\subsection{Study area}

For this work, the municipality of Inconfidentes is chosen, located to the south of the state of Minas Gerais, as shown in Figure 1.

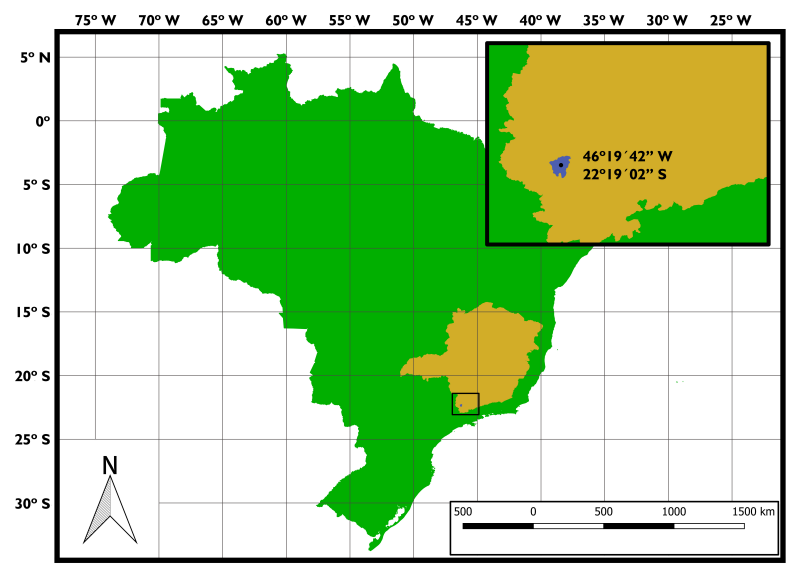

Figure 1. Study area - Inconfidentes/MG.

\subsection{RPA Used for Survey}

According to the manufacturer (DJI, 2016), Phantom 4 is a small size RPA, bearing the following characteristics:

- Weight (including battery and propellers): $1.380 \mathrm{~g}$; 
- Dimensions (diagonal - from end to wing): $350 \mathrm{~mm}$;

- Maximum Climbing Speed: $6 \mathrm{~m} / \mathrm{s}$;

- Maximum Descent Speed: $4 \mathrm{~m} / \mathrm{s}$;

- Maximum speed: $20 \mathrm{~m} / \mathrm{s}$;

- Maximum Range: 6 Km;

- Global Position System: GPS/GLONASS; and

- Maximum wind resistance: $10 \mathrm{~m} / \mathrm{s}$.

Phantom 4 features a 12 MPixel visible-range (RGB) camera, coupled with a gimbal, which ensures you get your images at the desired angle and with minimal vibration. The camera also allows shooting at up to $4 \mathrm{~K}$ resolution (Lacerda et al., 2019) and (DJI, 2016).

\subsection{Flight Planning and Image Preprocessing}

For flight planning, the Pix4DCapture (Pix4D, 2019) mobile app was used. The experiment was performed on November 11, 2018, with the conditions:

- Flight Height: 120m (from takeoff point);

- Imaged Area: 1,101 x 1,600 m;

- Front Cover: $80 \%$ and Side Cover: 60\%;

- Flight mode: 2D - One-way flight;

- Aircraft speed: $15 \mathrm{~m} / \mathrm{s}$;

- Camera Direction: $90^{\circ}$ (NADIR); and

- GSD expected: $5.25 \mathrm{~cm}$.

In Figure 2 the flight design data is presented.

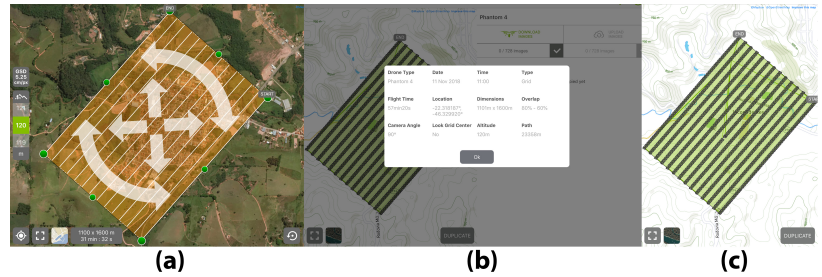

Figure 2. Data of Planning Flight. (a) flight planning. (b) project details. (c) the imaging performed.

In this flight, 721 georeferenced images were obtained and processed using Pix4D Mapper software (Pix4D, 2019). The Quality Report highlights the following information:

- Ground Sampling Distance (GSD) Average $6.03 \mathrm{~cm}$ (2.37 in);

- Covered Area: 2,305 Km2;

- Images Dataset: 721, 720 calibrated images;

- Camera Optimization: $2.45 \%$ relative difference between initial and optimized internal camera parameters;
- Control Points: 8 GCPs (3D), with average RMS error = $0.062 \mathrm{~m}$;

- Check Points: 3 CPs (3D); and

- Output Coordinate System: WGS 84 / UTM zone 23S (EGM 96 Geoid).

As a result of the image processing, the software generates an orthophoto mosaic and Digital Surface Model (DSM) - Figure 3.
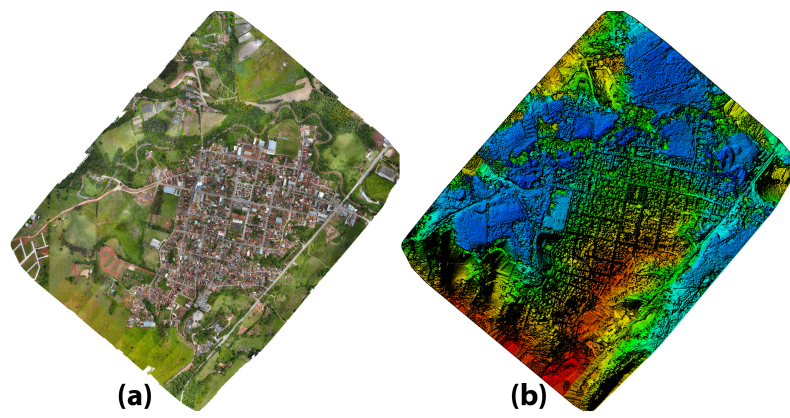

Figure 3. Processing Products: in (a) o Ortophoto mosaic and (b) DSM.

\subsection{Methodology}

In Figure 4, a summary of the methodology that has been used in this work is presented.

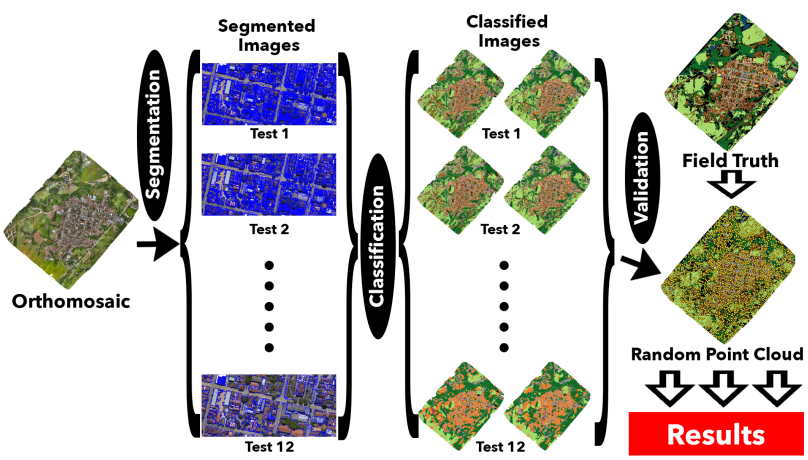

Figure 4. Methodology Summary

2.4.1 Image Segmentation. During the segmentation process, the image is subdivided into regions or objects. For this reason, the stop criterion of the algorithm depends on the problem at hand (Gonzalez, Woods, 2010).

Segmentation is very important in the image processing area because its input is images and its output is composed of features of those images (Gonzalez, Woods, 2010). In this work, the resulting orthophoto mosaic is segmented by 24 different parameters sets, and the resulting features were used during the image classification.

Segmentation aims at concentrating the information contained in images into homogeneous regions (objects), which are related to the problem under analysis. The quality of the segmentation depends on the selected algorithm and its parameters, and they are determined after successive tests on the image of interest (Geotecnologias, 2010). Thus, it is important to make a good choice of the segmentation parameters (Gonzalez, Woods, 2010). 
In this paper, the segmentation process is divided into two steps: firstly, the Multi-resolution Segmentation (MRS) algorithm is used; and then we use the Spectral Difference Segmentation $(S D S)$ algorithm. Those techniques yielded good results in other works (Anjos et al., 2017b).

Many tests are performed with different segmentation parameters on the first step, to evaluate the classification accuracy from different segmentations. After that, the second step of the segmentation is performed, to analyze the difference in the result of the image processing.

A. Multi-resolution Segmentation (MRS). MRS is basically a procedure of heuristic optimization, which locally minimizes the heterogeneity mean of the objects in the image, according to a given resolution (Definiens, 2007). In other words, it is possible to understand that the multi-resolution approach analyzes the objects in different resolution levels. Smaller objects can be analyzed in finer image resolutions, whereas bigger objects may be appropriately handled in coarser resolution. The segmentation may be accomplished in many resolutions, by varying the parameters of the segmentation algorithm (Anjos et al., 2015) and (Leonardi, 2010).

Basically, the parameters that influence MRS are:

- Scale Parameter determines the maximum heterogeneity of the resulting image objects. For heterogeneous data, the resulting objects for a given scale parameter are smaller, when compared to more homogeneous data. When one changes the scale parameter value, the size of the resulting objects also changes (Definiens, 2007).

- Homogeneity Composition Criterion is used as synonym of minimized heterogeneity (Definiens, 2007). On the software we use in this work, two parameters define this value: shape e compactness.

B. Spectral Difference Segmentation (SDS). SDS was devised to refine the pre-existing segmentation, and it is not used to generate a new segmentation in the pixel level (Definiens, 2007). (Definiens, 2007). Under the SDS approach, neighboring objects are merged based on the absolute difference amongst their mean grey level values. This difference is the threshold defined by the user by considering the image characteristics to be distinguished (Bartani, Rossetti, 2014). This parameter is defined as Maximum Spectral Difference (MSD).

C. Tests parameters. In this work, the main objective is to verify the influence of the segmentation on the classification. So, we define 12 segmentation tests, by varying scale, shape and compactness parameters.

For tests 1 to 9 , the scale parameter is kept in 50, whereas shape and compactness parameters have the values: $0.1,0.5$ and 0.8 .

For the tests 10 to 12 , we varied the scale parameter value, keeping both shape and compactness parameters in 0.5 (as used in test 5).

For each test, the segmentation is accomplished in two steps: MRS and SDS. For all the SDS tests, the MSD parameter is kept in 10.

Table 1 shows the scale, shape and compactness parameters used in the 12 tests, as well as the number of segments after each segmentation. As a result, there are 24 segmented images.
Table 1. Summary of Tests Performed

\begin{tabular}{|c|c|c|c|c|c|}
\hline & \multicolumn{3}{|c|}{ Parameters } & \multicolumn{2}{c|}{ Num of Segments } \\
\hline Test & Scale & Shape & Comp. & Step 1 & Step 1+2 \\
\hline 1 & 50 & 0.1 & 0.1 & 484,106 & 291,892 \\
\hline 2 & 50 & 0.1 & 0.5 & 501,362 & 287,328 \\
\hline 3 & 50 & 0.1 & 0.8 & 521,761 & 280,302 \\
\hline 4 & 50 & 0.5 & 0.1 & 374,250 & 156,601 \\
\hline 5 & 50 & 0.5 & 0.5 & 414,800 & 150,881 \\
\hline 6 & 50 & 0.5 & 0.8 & 457,698 & 144,847 \\
\hline 7 & 50 & 0.8 & 0.1 & 251,383 & 74,659 \\
\hline 8 & 50 & 0.8 & 0.5 & 337,385 & 75,376 \\
\hline 9 & 50 & 0.8 & 0.8 & 428,510 & 76,359 \\
\hline 10 & 100 & 0.5 & 0.5 & 114,069 & 48,465 \\
\hline 11 & 300 & 0.5 & 0.5 & 15,528 & 8,673 \\
\hline 12 & 800 & 0.5 & 0.5 & 2,449 & 1,570 \\
\hline
\end{tabular}

2.4.2 Ground-Truth, Classes, and Sample Collection. To perform the validation of results, the ground-truth was created by eliciting information on-site and by visual interpretation of the image. Furthermore, complementary flights were performed to improve the precision of the ground-truth.

After that, 21 classes are considered in this work. Figure 5 shows the ground-truth and the classes.

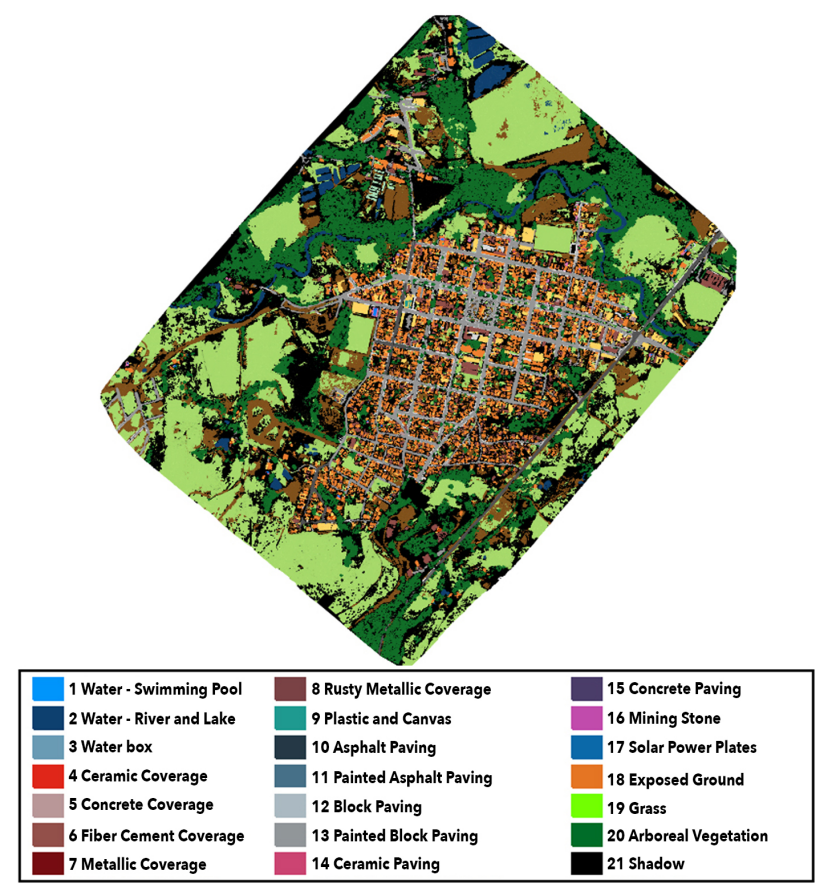

Figure 5. Ground-truth and classes

A. Sample Collection. The classification performed in this work is supervised. Table 1 shows the parameters of Test 1 , from which 1,841 training samples are generated.

2.4.3 Attribute Selection. After the segmentation, the following attributes were chosen to be exported for use in the image classification process: Mean (RGB), Standard Deviation (RGB), Brightness, Maximum difference, Area, Border length, Length, Border index, Compactness, and Class Name.

There is a file for each variation of segmentation parameters. Twenty four in total. Each file contains 14 features and the number of instances, as described in Table 1. 
2.4.4 Image Classification. We use Random Forest (RF) (Breiman, 2001) to perform the classification. RF uses many decision trees not related to each other. From the training data, different random sample sets are generated, one for each decision tree, yielding, thus, independent trees (Anjos et al., 2017a). In the literature, many authors claim that RF accuracies outperform other classifiers. According to (Biau et al., 2008), Random Forest has excellent results in practical problems.

2.4.5 Random Points. In order to validate the classification results, we use the software QGIS 2.18 (QGIS, 2019). A cloud with 4,000 points is created over the ground-truth image, however, 2,500 points lie on the image, whereas 1,500 points are concentrated over the outer regions of the image, as shown in Figure 6.

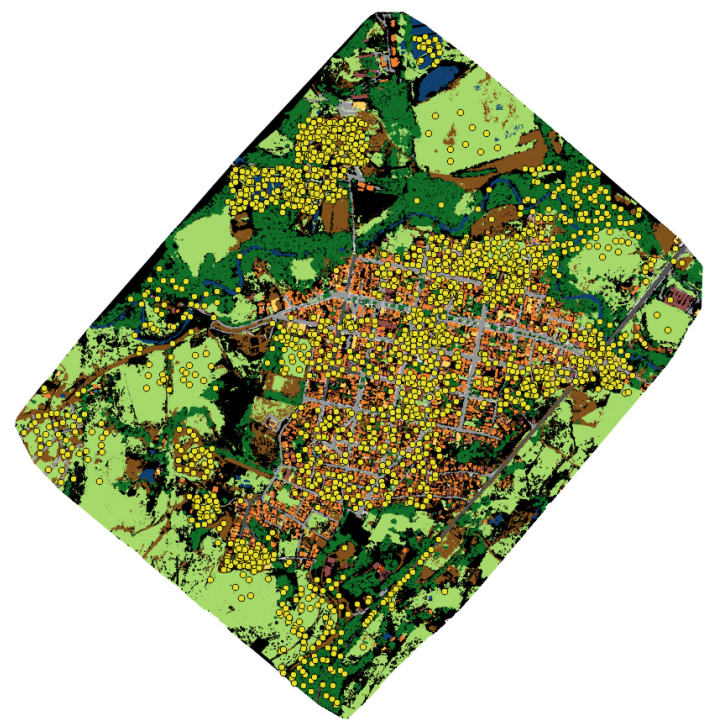

Figure 6. Random Point Cloud over the ground-truth

The classification accuracy is assessed by comparing the intersection among the points of the ground-truth and the classified image. After that, the confusion matrix is calculated, from which the Overall Accuracy and Kappa Index are computed.

2.4.6 Evaluation of the Classification. The Overall Accuracy of the classified image indicates its reliability. Thus, a statistical evaluation to define accuracy is employed (Bernardes, 2006) and (Figueiredo, Vieira, 2007).

According to (Bernardes, 2006) and (Figueiredo, Vieira, 2007), when one analyzes Remote Sensing data, it is fundamental to proceed to the assessment of the thematic precision, because it is important to know how reliable the data from thematic maps are. Moreover, with the confusion matrix, it is possible to find inaccuracies in the class-pixel assignment.

By analyzing the confusion matrix (Figueiredo, Vieira, 2007) and (Foody, 2002), it is possible to get: Overall Accuracy, Kappa Index, Productor Precision, User Precision, Inclusion Error, Omission Error, Kappa Index for Class, etc. Here, we use only the Overall Accuracy and Kappa Index.

The Overall Accuracy is given by the sum of the elements of the main diagonal of the confusion matrix divided by the number of data samples (Figueiredo, Vieira, 2007). In other words, only the number of correctly classified samples (main diagonal) and the total number of samples are considered.
For the calculation of the Kappa Index (K), all the entries of the confusion matrix are used. Thus, $\mathrm{K}$ is more adequate to verify the classification accuracy (Congalton, 1991).

\section{RESULTS AND DISCUSSION}

From each segmentation type, there is a classified image. Twenty four in total. Figure 7 shows the images classified using the segmentation parameters of Test 1 . And Figure 8 exhibits images of Test 12.
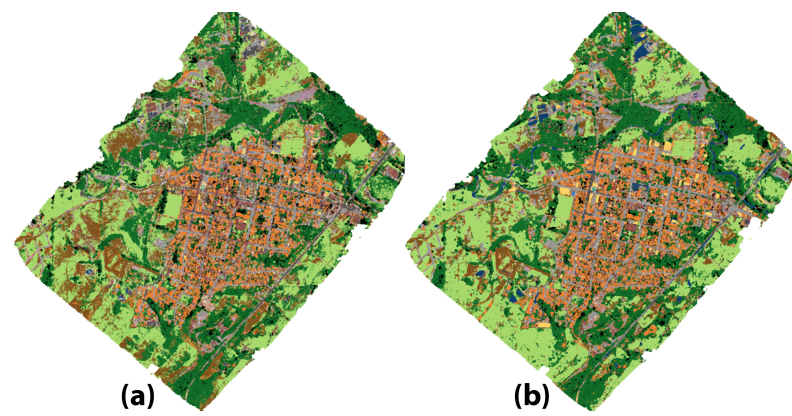

Figure 7. Classified Images Test 1. (a)Step 1 and (b)Step 1+2.

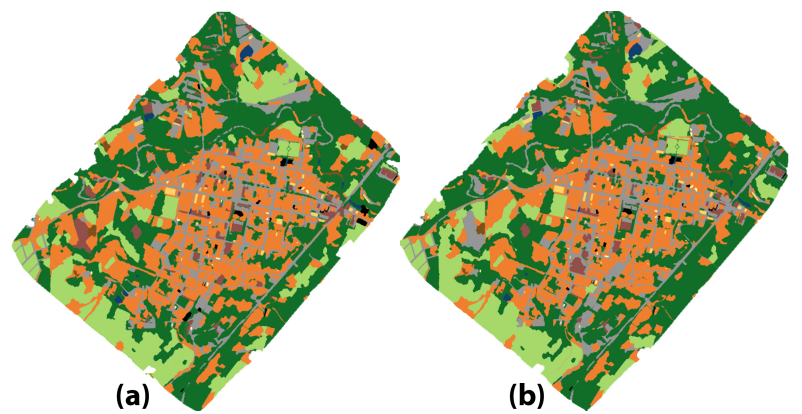

Figure 8. Classified Images - Test 12. (a)Step 1 and (b)Step 1+2.

We use the random point cloud over the area under analysis to measure the accuracy of the classification of the twenty-four images. Thus, it is possible to verify the intersection among the points.

By taking into account the point in the ground-truth and classified images, it is possible to evaluate the confusion matrix, from which the Overall Accuracy and Kappa Index are calculated for each classified image.

Table 2 shows the Overall Accuracy (OA) and Kappa Index for the tests considering only Step 1 . Moreover, it is shown the processing time, in seconds, for the classifier setting and the classification. In Table 3 we see the values for the tests taking into account Steps 1 and 2.

According to Tables 1, 2 and 3 and Figures 9 and 10, one may infer that processing time for model setting and the classification of the 24 images is relatively low and similar (all of them lie in a region comprised by 2 standard-deviations). Classification time, in almost all cases, is directly related to the segments contained in the file to be classified, that is, the bigger the number of segments, the longer the processing time. In Figure 11, it is possible to see that the two curves have similar behavior.

Each correspondent row in Tables 2 and 3 represents an experiment with the same parameters. For a given parameter 
Table 2. Results obtained in classification process - Step 1.

\begin{tabular}{|c|c|c|c|c|}
\hline Test & OA & Kappa & model (sec) & classif (sec) \\
\hline 1 & $74.50 \%$ & 0.694 & 1.16 & 217.73 \\
\hline 2 & $75.17 \%$ & 0.701 & 1.11 & 204.5 \\
\hline 3 & $73.18 \%$ & 0.680 & 1.13 & 213.99 \\
\hline 4 & $67.66 \%$ & 0.624 & 1.08 & 156.42 \\
\hline 5 & $65.73 \%$ & 0.605 & 1.05 & 169.55 \\
\hline 6 & $64.18 \%$ & 0.591 & 1.06 & 190.97 \\
\hline 7 & $65.12 \%$ & 0.594 & 1.09 & 101.57 \\
\hline 8 & $62.14 \%$ & 0.566 & 1.06 & 136.62 \\
\hline 9 & $59.17 \%$ & 0.542 & 1.06 & 172.83 \\
\hline 10 & $66.45 \%$ & 0.598 & 1.11 & 47.14 \\
\hline 11 & $68.54 \%$ & 0.611 & 1.02 & 7.44 \\
\hline 12 & $63.19 \%$ & 0.543 & 1.03 & 0.97 \\
\hline
\end{tabular}

Table 3. Results obtained in classification process - Step $1+2$.

\begin{tabular}{|c|c|c|c|c|}
\hline Test & OA & Kappa & model $(\mathbf{s e c})$ & classif $(\mathbf{s e c})$ \\
\hline 1 & $84.16 \%$ & 0.796 & 1.02 & 121.34 \\
\hline 2 & $86.87 \%$ & 0.827 & 1.03 & 122.27 \\
\hline 3 & $85.04 \%$ & 0.806 & 1.05 & 116.76 \\
\hline 4 & $82.28 \%$ & 0.774 & 1.19 & 68.08 \\
\hline 5 & $82.17 \%$ & 0.774 & 1.03 & 63.15 \\
\hline 6 & $80.57 \%$ & 0.756 & 1.09 & 59.74 \\
\hline 7 & $79.42 \%$ & 0.740 & 1.00 & 33.39 \\
\hline 8 & $77.32 \%$ & 0.717 & 1.05 & 32.16 \\
\hline 9 & $75.11 \%$ & 0.693 & 1.14 & 33.20 \\
\hline 10 & $76.77 \%$ & 0.708 & 1.09 & 20.35 \\
\hline 11 & $69.81 \%$ & 0.623 & 1.03 & 3.59 \\
\hline 12 & $63.63 \%$ & 0.548 & 1.03 & 0.92 \\
\hline
\end{tabular}

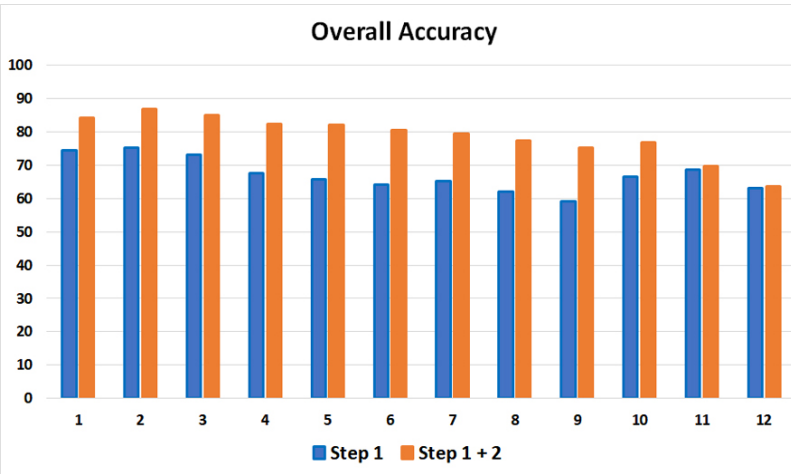

Figure 9. Overall Values

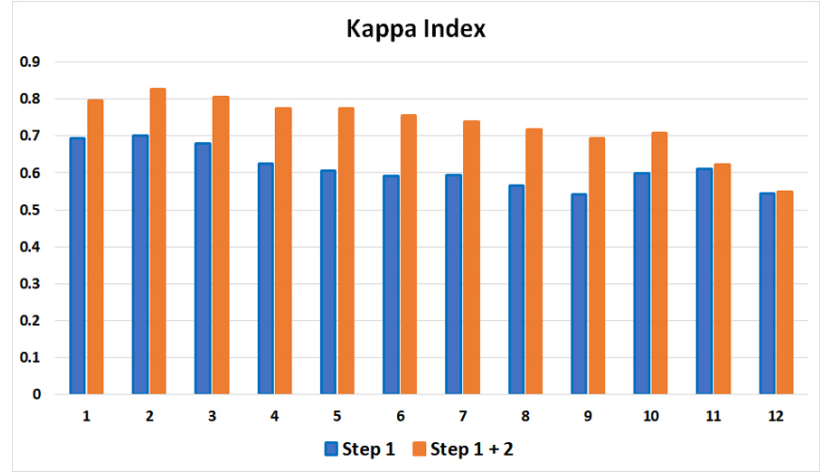

Figure 10. Kappa Index Values

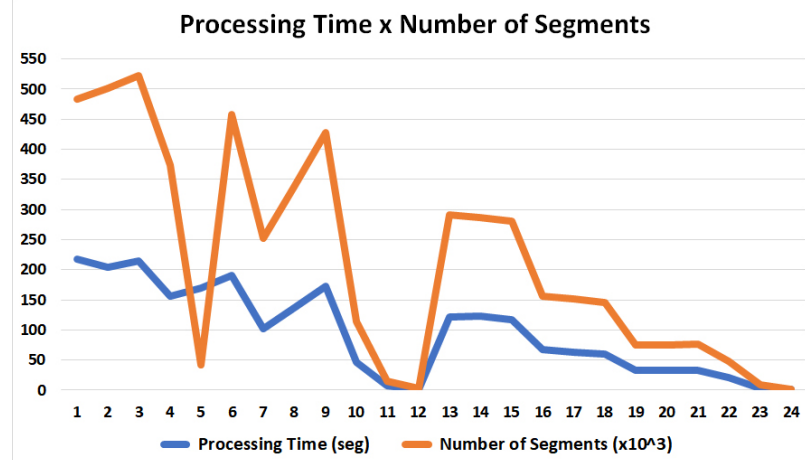

Figure 11. Processing Time Vs Number of Segments

set, it is possible to see that the two-step-procedure (MRS + SDS) has higher Overall Accuracy, higher Kappa Index and shorter processing time when compared to the Step 1 method. Figure 12 shows the difference between the Overall Accuracy and Kappa Index of Step $1+$ Step 2 method and the Overall Accuracy and Kappa Index of Step 1 method.

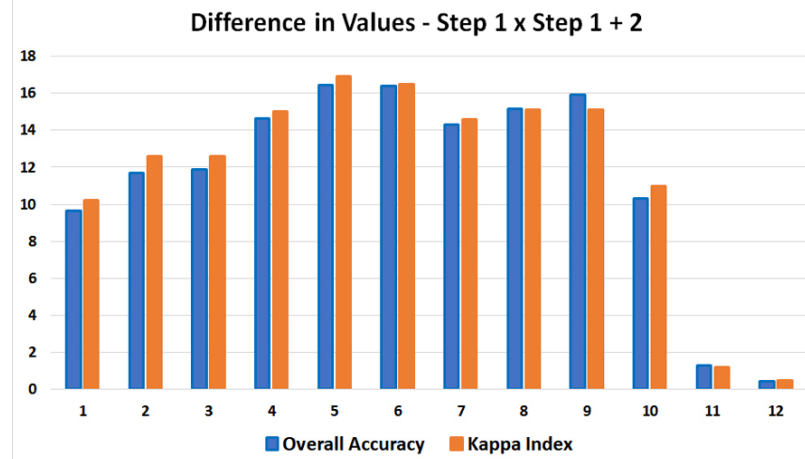

Figure 12. Difference of Overall Accuracy and Index Values between the Step 1+2 method and Step 1 method.

\section{CONCLUSIONS}

According to the data analysis performed in this paper, one may state that the segmentation parameters exert influence on the final classification. For this reason, it is important to test different parameters set to find a reasonable setting to work with.

The two-step segmentation (MRS + SDS) improved the results in all tests. Thus, this method is highly recommended. Furthermore, this combination also reduces processing time.

For the data used in this paper, there is no direct relation between the number of segments and the Overall Accuracy. For instance, Test 9, with one step segmentation, has the smallest Overall Accuracy, and this test is in the fifth position in terms of the number of segments.

We saw that there is a trade-off between the Overall Accuracy (or Kappa Index) and processing time. For example, Test 12, with its two-step-segmentation, yielded an image with only 1,570 segments and processing time lesser than 2 seconds, with Overall Accuracy of $63.63 \%$.

Finally, one can conclude that the Test 2 had the best performance $($ Overall Accuracy $=86.87 \%$ e Kappa Index 
$=0.827$ ) with the segmentation in two steps, with MRS parameters Scale $=50$; Shape $=0.1$ e Compactness $=0.5$, followed by Difference Segmentation (SDS), with Maximum Spectral Difference $=10$.

\section{REFERENCES}

Anjos, C. S. et al., 2015. Identificação de materiais urbanos por meio de métodos inovadores de classificação de imagens. Anais do XVII Simpósio Brasileiro de Sensoriamento Remoto - SBSR, INPE, 1, p. 4377-4384.

Anjos, C. S. et al., 2017a. Análise do Nível de Legenda de Classificação de Áreas Urbanas Empregando Imagens Multiespectrais e Hiperespectrais com Métodos Árvore de Decisão C4.5 e Floresta Randômica. Boletim de Ciências Geodésicas, 23.

Anjos, C. S. et al., 2017b. Classification of urban environments using Feature Extraction and Random Forest. 2017 IEEE International Geoscience and Remote Sensing Symposium (IGARSS), 1, p. 1205-1208.

Bartani, T. C., Rossetti, D. F., 2014. Segmentação por diferença espectral para extração de relevos em planícies fluviais amazônicas. Revista Geonorte, Edição Especial 4, 10, p. 291-296.

Bernardes, T., 2006. Caracterização do ambiente agrícola do Complexo Serra Negra por meio de sensoriamento remoto e sistemas de informação geográfica. Dissertação de Mestrado - Universidade Federal de Lavras, 1, 119 p.

Biau, G. et al., 2008. Consistency of Random Forests and other averaging classifiers. Journal of Machine Learning Research, 9, p. 2015-2033.

Breiman, L., 2001. Random Forest. Machine Learning. Statistics Department - University of California, 1, 33 p.

Congalton, R. G., 1991. A review of assessing the accuracy of classifications of remotely sensed data. Remote Sensing of Environment, 37, p. 35-46.

Definiens, 2007. Definiens Developer7: Reference Book. 1, 7.0.2.936 edn, Definiens, Munich, Germany.

DJI, 2016. Phantom 4: User Manual. 1, 1.2 edn, DJI. Disponível em: http://www.dji.com/product/phantom-4.

Figueiredo, G. C., Vieira, C. A. O., 2007. Estudo do comportamento dos Índices de Exatidão Global, Kappa e Tau, comumente usados para avaliar a classificação de imagens do sensoriamento remoto. Anais do XIII Simpósio Brasileiro de Sensoriamento Remoto - SBSR, INPE, p. 5755-5762.

Foody, G. M., 2002. Status of land cover classification accuracy assessment. Remote Sensing of Environment, 80, p. 185-201.

Geotecnologias, $\quad$ S., $\quad 2010 . \quad$ Classificação Orientada a Objeto - considerações. site: geotecnologias.wordpress.com/2010/08/19/

classificacao-orientada-a-objeto-consideracoes.

Gonzalez, R. C., Woods, R. E., 2010. Processamento Digital de Imagens. 1, 3 edn, Pearson, São Paulo.

Granemann, E., 2018. Os desafios da Regulamentação do uso de Drones no Brasil. site: droneshowla.com, 1, 1 p.
Lacerda, M. G. et al., 2017. O Emprego de Árvore de Decisão para a Identificação e Classificaçao de ZLs e ZPHs em Imagens Obtidas por ARPs de Pequeno Porte. Anais do XIX Simpósio de Aplicações Operacionais em Área de Defesa - SIGE, 1, p. 98 102.

Lacerda, M. G. et al., 2019. Influência dos Parâmetros de Segmentação de Imagem em Ortofotomosaicos confeccionados a partir de fotografias obtidas por Aeronaves Remotamente Pilotadas de Pequeno Porte. Anais do XIX Simpósio Brasileiro de Sensoriamento Remoto, 1, 4 p.

Leonardi, F., 2010. Abordagens cognitivas e mineração de dados aplicadas a dados ópticos orbitais e de laser para a classificação de cobertura do solo urbano. Dissertação de Mestrado - Instituto Nacional de Pesquisas Espaciais, INPE, $1,164 \mathrm{p}$.

Pix4D, 2019. Pix4D Products. site: https://www.pix4d.com.

QGIS, 2019. QGIS. site: https://www.qgis.org/en/site/. 